\title{
1 Bacterial glycogen provides short-term benefits in changing
}

\section{2 environments}

3 Karthik Sekar $^{1, \dagger}$, Stephanie M. Linker ${ }^{1,2, \dagger}$, Jen Nguyen ${ }^{3,4}$, Alix Grünhagen ${ }^{1}$, Roman Stocker ${ }^{3}$,

$4 \quad$ Uwe Sauer ${ }^{1, *}$

$5{ }^{1}$ Institute of Molecular Systems Biology, Department of Biology, ETH Zurich, 8049 Zurich,

6 Switzerland.

$7 \quad{ }^{2}$ Laboratory of Physical Chemistry, Department of Chemistry, ETH Zurich, 8049 Zurich,

8 Switzerland.

$9{ }^{3}$ Institute of Environmental Engineering, Department of Civil, Environmental and Geomatic

10 Engineering, ETH Zurich, 8049 Zurich, Switzerland.

$11{ }^{4}$ Microbiology Graduate Program, Massachusetts Institute of Technology, Cambridge 02139,

12 Massachusetts, USA.

$13 \dagger$ denotes equal contribution

14 *To whom correspondence should be addressed: sauer@imsb.biol.ethz.ch

\section{Abstract}

17 Changing nutritional conditions challenge microbes and shape their evolutionary optimization. Here we investigated the role of glycogen in dynamic physiological adaptation of Escherichia coli to fluctuating nutrients following carbon starvation using real-time metabolomics. We found significant metabolic activity remaining after the depletion of environmental glucose that was linked to a rapid utilization of intracellular glycogen. Glycogen was depleted by $80 \%$ within minutes of glucose starvation and similarly replenished within minutes of glucose availability. These fast timescales of glycogen utilization correspond to the short-term benefits that glycogen provided to cells undergoing various physiological transitions. Cells capable of utilizing glycogen exhibited shorter lag times than glycogen mutants when starved between different carbon sources. The ability to 
utilize glycogen was also important for the transition between planktonic and biofilm lifestyles and enabled increased glucose uptake during pulses of limited glucose availability. While wild-type and mutant strains exhibited comparable growth rates in steady environments, mutants deficient in glycogen utilization grew more poorly in environments that fluctuated on minute-scales between carbon availability and starvation. Altogether, these results highlight an underappreciated role of glycogen to rapidly provide carbon and energy in changing environments, thereby increasing survival and competition capabilities in fluctuating and nutrient poor conditions.

\section{Introduction}

Microbes must adapt to and compete under changing nutrient conditions. Instead of a wellmixed environment, bacteria in the wild often experience a feast-or-famine existence. Many microbial habitats are characterized by longer periods of nutrient starvation, intermittently punctuated by nutrient availability (Stocker, 2012). Thus, microorganisms face strong selective pressure to quickly resume growth when nutrients once again become available, and a diversity of strategies has evolved (Bergkessel, Basta, \& Newman, 2016; Shoemaker \& Lennon, 2018). Generally, these strategies involve the accumulation of unused resource that are labile and quickly activated when richer nutrient environments permit fast growth. For example, Escherichia coli facilitate rapid physiological transitions to higher quality nutrient conditions by maintaining a pool of ribosomes that only become translationally active as available nutrient becomes more abundant (Kohanim et al., 2018; Li et al., 2018; Metzl-Raz et al., 2017; Mori, Schink, Erickson, Gerland, \& Hwa, 2017). E. coli also often feature additional enzymatic capacity beyond that immediately required (Davidi \& Milo, 2017; O'Brien, Utrilla, \& Palsson, 2016; Sander et al., 2019), and accumulate metabolically costly amino acids from protein degradation during starvation, which are then rapidly used for RNA 
52

and protein synthesis upon the resumption of growth (Link, Fuhrer, Gerosa, Zamboni, \&

Sauer, 2015). Strategies in other organisms include accumulation of alanine dehydrogenase in

Bacillus subtilis to expedite growth after shifts to different environments (Mutlu et al., 2018), and the accumulation of methane oxidases in the methanotroph, Methyloprofundus sedimenti, induced by starvation in an effort to rapidly convert the next available methane into methanol (Tavormina et al., 2017).

Glycogen, a polymer of glucose, is another stored resource across evolutionarily divergent species. While the role of glycogen in mammalian cells is well-established as a temporary sugar reserve, the role of glycogen in bacteria such as E. coli has been less clear. Earlier studies have linked glycogen with long-term survival, contributing an energy source when the environment does not (Wilson et al., 2010); whereas, others discuss it as a temporary resource used during the physiological transitions necessitated by dynamic environmental conditions (Morin et al., 2017; Seok et al., 1997; Yamamotoya et al., 2012). Some studies combine the two perspectives, describing a role for glycogen that contributes to survival or maintenance in environments that frequently fluctuate in nutrient availability (Bourassa \& Camilli, 2009;

Jones et al., 2008). The concept of glycogen as a nutrient "bank" from which cells withdraw and deposit (Bertrand, 2019) summarizes the prevailing view about the role of glycogen in bacteria; however, for how long after starvation glycogen continues to supply the cell and towards what physiological processes it is used remains to be clarified.

Here, we describe the temporal dynamics of glycogen synthesis and breakdown between periods of nutrient availability and starvation. Using real-time metabolomics (Link et al., 2015) and glycogen measurements, we discovered that glycogen is depleted by more than $80 \%$ within 10 minutes of entry into starvation conditions and replenished after 2 min of 
nutrient availability. By comparing wild-type cells with cells unable to use glycogen, we found that glycogen shortens lag times when switching between carbon sources, enhances uptake when glucose is limited and facilitates the transition from planktonic to biofilm lifestyles. Importantly, this advantage conferred by glycogen existed only in dynamic or fluctuating environments; glycogen-deficient cells performed comparably to glycogen wildtype cells in steady environments. Our results suggest a role for glycogen during physiological transitions that involve starvation. We propose that glycogen serves as a shortterm resource, consumed in the minutes after the onset of starvation. The short-term uses of glycogen may lead to long-term benefits; though from our data, it is unlikely that glycogen stores alone work to directly support bacterial maintenance in extended periods of nutrient starvation.

\section{Results}

\section{Cells utilize glycogen upon carbon starvation}

To investigate the role of glycogen during starvation, we designed a real-time metabolomics experiment to compare the metabolic changes across a transition into starvation of $E$. coli wild-type and a mutant unable to utilize glycogen. Specifically, we harvested minimal medium mid-log phase cultures at an optical density of $600 \mathrm{~nm}(\mathrm{OD})$ of 0.8 by fast filtration (Rabinowitz \& Kimball, 2007) and resuspended them in the same medium but with a limiting amount of glucose as the sole carbon source (Fig 1A). We designed the medium such that the culture would deplete all carbon within 30-40 min (Supplementary Information). Across the transition into starvation, we measured over 100 metabolites as the sum of extra- and intracellular molecules every 15 s using real-time metabolomics (Link et al., 2015). In wildtype cells, the ion corresponding to hexoses such as glucose was depleted within 30-40 min (Fig 1B). Several ions annotated to central carbon metabolites diminished immediately after 
102 glucose was depleted (Figure S1), but others such as hexose phosphate and amino acids

103 remained stable or even increased such as the tricarboxylic acid (TCA) cycle intermediate

104 (iso)citrate (Fig 1B). The large number of stable or even increased metabolites suggest

105 ongoing metabolism that is supplied from another source. Given the stable concentration of

106 hexose phosphates and that the first step of glycogen hydrolysis releases glucose-1-phosphate,

107 we hypothesized that glycogen usage may supply metabolism. Indeed, by performing the

108 same experiment with the $g \lg P$ mutant that is unable to use glycogen, we observed a similar

109 depletion of glucose across the shift into starvation. In contrast to the wild-type, however, the

110 level of hexose phosphates in the glgP mutant depleted concurrently with glucose (Fig 1B).

111 Additionally, other metabolite levels were reduced compared to the wild-type (Fig 1B).

112 Glycogen utilization did not explain stable levels of all ions during transition to starvation

113 (Figure S1B); specifically, the abundances of ions corresponding to metabolites 3-

114 propylmalate, isopropylmaleate, and orotate remained roughly constant in both strains.

115 Nonetheless, the depletion of hexose phosphates in the wild-type versus $g \lg P$ strain implicates

116 the utilization of glycogen within minutes of the transition into starvation.

To test the hypothesis that a rapid onset of glycogen breakdown serves as an immediate fuel,

we measured cellular glycogen content from the onset of starvation to 50 min after starvation

120 (Figure 2A). We found that glycogen content diminished by $80 \%$ within the first 10 min of 
content reached a steady glycogen level within 2 min (Figure 2B). Thus, glycogen synthesis and degradation occur on minute time scales, suggesting that glycogen serves a potential role as a short-term energy storage in microbes, akin to the mammalian system.

To elucidate the complete dynamics of the metabolic response to glycogen degradation and synthesis, we designed a more controlled real-time metabolomics experiment. Specifically, we fed glucose to a culture that was starved for $30 \mathrm{~min}$ at a constant rate of $8 \mathrm{mmol}$ glucose/g dry weight/h for $5 \mathrm{~min}$, then we turned off the feed pump, and we measured metabolism for an additional $80 \mathrm{~min}$. The feedrate of $8 \mathrm{mmol} / \mathrm{g} / \mathrm{h}$ was chosen to be well below the maximum uptake rate of E. coli (Monk et al., 2016; Sekar et al., 2018), meaning that glucose will not abundantly accumulate in the medium. Consistent with this design, the ion corresponding to glucose depleted within 1-2 min after the feed ceased (Figure S2). We observed a sudden drop after glucose depletion in all other metabolite concentrations including hexose-6-phosphate, (iso)citrate, and other central carbon metabolites for both wild-type and $g \lg P$ (Figure 3). In contrast to the $g l p P$ mutant, several metabolites within or near the TCA cycle exhibited a secondary response in the wild-type. After initial depletion, isocitrate, in particular, immediately arises again within 5 min to a level near that of the glucose fed state. This "bounce" effect was also observed prominently in glutamine, glutamate, malate, and aspartate, as indicated by the green arrows. That the bounce effect was observed primarily in metabolites within or near the TCA cycle (Figure 3, Figure S3) suggests that glycogen is used to fuel respiration right after the onset of starvation.

Overall, we posit that glucose starvation initiates glycogen utilization, both during gradual glucose depletion as in the earlier experiment or the nearly instantaneous depletion here. These observations are consistent with known and suggested interactions of glycogen 
152 phosphorylase and glucose uptake-related proteins (Seok et al., 1997; Tian, Fauré, Mori, \&

153 Matsuno, 2013); specifically, the HPr protein involved in glucose uptake positively activates

154 glycogen phosphorylation allosterically. A strongly stimulatory effect occurs when HPr is

155 dephosphorylated as is typical for starvation. The rapid timescale enabled by allosteric

156 regulation is consistent with our data, which suggests that decreasing glucose uptake rapidly

157 triggers glycogen usage.

160 The minute-scale liquidation of glycogen led us to ask whether glycogen enables cells to accommodate sudden environmental change. To evaluate how glycogen affects the ability to adapt to new environments, we tested two biologically relevant transitions: a change of nutrient source and the transition from planktonic to biofilm growth. As a control, we first tested the influence of glycogen in stable environments and determined that the difference in the steady-state growth rate of wild-type cells versus different glycogen mutants was small (within 15\%; Figure 4A). Next, we performed a nutrient-shift experiment where wild-type and $g \lg P$ mutant were grown to mid-log phase (OD 0.4) in glucose medium. After centrifugation and washing, cultures were rapidly transferred into a medium with acetate as the sole carbon source, either directly or with a transitory 30 min period of starvation in carbon-free medium. Without starvation, the time to resume full growth after the switch (i.e. the lag time) was identical for wild-type and mutant (Figure 4B). With an intermittent starvation period, however, the glycogen mutant exhibited a roughly doubled lag time $(\sim 220$

173 min versus $\sim 110$ min) with respect to the wild-type. To test whether this reliance on glycogen was also required during less abrupt transitions, we performed a modified lag time experiment, where acetate was added either $60 \mathrm{~min}$ before or $60 \mathrm{~min}$ after glucose was 
177 found comparable lag times between the glycogen mutant and wild type without starvation.

178 However, after a period of starvation, the lag time of the glycogen mutant was again significantly prolonged with respect to the wild-type. Presumably, the wild-type has a shorter lag time after starvation because they either initiate the adaptation already before depletion of the primary carbon source or scavenge previously excreted carbon sources such as acetate (Mandel \& Silhavy, 2005; Rahman, Hasan, Oba, \& Shimizu, 2006; Wei, Shin, LaPorte, Wolfe, \& Romeo, 2000). Our data suggests that cells unable to use glycogen are consequently slower in completing the necessary molecular adaptions for full growth in new conditions.

Likely, these cells are deprived of alternative carbon and/or energy sources when experiencing a change in carbon source.

The transition from planktonic to sessile (biofilm) lifestyles represent another adaptation that requires substantial restructuring of cellular physiology. Biofilm formation is characterized by three phases: attachment, maturation, and dispersal (Weiss, Obied, Kalkman, Lammertink, \& van Leeuwen, 2016). We focused on the attachment phase, which is characterized by the decrease of planktonic cells. A common method for estimating the concentration of planktonic bacteria relies on measuring the $\mathrm{OD}_{600}$. When stationary phase E. coli was cultured without shaking, the number of planktonic cells decreased by $89 \%$ within 18 hours (Figure 4D). The $g \lg P$ and $g \lg A$ mutants, in contrast, remained largely planktonic even after 18 hours (26\% and 36\% decrease, respectively). Therefore, wild-type cells have either an increased attachment rate or an increased mortality rate in comparison to the glycogen mutant. The latter is unlikely as our previous experiments have indicated metabolic, viable activity for cells well into starvation. Biofilm formation is induced by nutrient starvation and inhibited by glucose addition (Thomason, Fontaine, De Lay, \& Storz, 2012; Zhao et al., 2017). We 
201

202

203

204

205

206

207

208

209

210

211

212

213

214

215

216

217

218

219

220

221

222

223

224

225

therefore reason that glycogen facilitates the attachment phase of biofilm formation under starvation conditions, here by providing resources for matrix protein or flagella production.

\section{Glycogen utilization confers a growth advantage in dynamic nutrient environments}

Given the importance of glycogen during physiological transitions, we sought to establish the growth advantage conferred by glycogen utilization under controlled, dynamically changing conditions. By coupling microfluidics and time-lapse imaging, we monitored the volumetric growth of individual E. coli cells under fluctuating and steady nutrient supply. The fluctuating environment consisted of $30 \mathrm{~s}$ long nutrient pulses followed by 5 min of carbon starvation, whereas in the steady environment the carbon source was continuously replenished (Figure 5A). In both environments, precise control over the nutrient signal was maintained by flowing medium over surface-attached cells and switching between two media when generating a pulse (Nguyen, Fernandez, et al., 2019; Sekar et al., 2018). In these environments, we competed the YFP-labeled wild-type and the CFP-labeled glgP mutant and monitored their growth through image analysis.

In fluctuating environments, cells capable of consuming glycogen had an apparent growth advantage over those that could not. From time-lapse images, YFP-labeled wild-type cells visibly increased in cell mass and often divided, while the CFP-labeled $g l g P$ mutant hardly grew in size (Figure 5B). We then quantified single-cell growth rate as the rate at which cell volume exponentially doubles, as assessed from image frames captured 3 min apart. In fluctuating environments, these quantifications yielded maximum specific growth rates of $0.28 \pm 0.04 \mathrm{~h}^{-1}$ and $0.13 \pm 0.03 \mathrm{~h}^{-1}$ for wild-type and mutant strains, respectively, whereas in steady environments, the maximum specific growth rates of the two strains were indistinguishable (Figure 5C). To summarize, the ability to utilize glycogen enhances growth 
in fluctuating environments, thereby substantiating a key role for glycogen as an immediately available resource across changing environments.

\section{Glycogen utilization enable improved nutrient uptake capability}

So far, we have established that glycogen utilization confers a growth advantage in dynamic environments by providing energy and carbon in nutrient poor transition phases. It is not clear which cellular functions are supplied by the freed carbon from liquidated glycogen beyond biofilm faculties. Nevertheless, we hypothesized that the at least some of the freed carbon would lead to better uptake ability, a paramount survival attribute in scant environments. To measure the cellular ability for nutrient uptake, we used real-time metabolomics to monitor glucose uptake while switching the cells between starvation and pulses of glucose (Sekar et al., 2018). As in the antecedent study, we observed rapid assimilation of glucose, as indicated by the detected levels of the ion corresponding to glucose (Figure 6A). Each pulse showed an instantaneous increase of glucose concentration followed by depletion caused by bacterial consumption. Fitting a Michaelis-Menten model to the glucose consumption, where the uptake rate equates to the $V_{\max }$ of the fit (Figure 6B), revealed a much lower maximum capacity for glucose uptake in the glgP mutant compared to the wild-type (Figure 6C).

To test whether the difference in uptake capacity stemmed primarily from the carbon release in glycogen, we simulated the carbon release by providing a short dose of carbon by feeding glucose at $8 \mathrm{mmol} / \mathrm{g} / \mathrm{h}$ for $5 \mathrm{~min}$ (Figure 6A), after the first set of limiting glucose pulses.

Consistent with our hypothesis, the glucose uptake capacity remained high for the wild-type but improved significantly for the $g \lg P$ mutant. Thus, the uptake capability does appear to originate from access to a nutrient source during starvation, whether its internal glycogen or additional carbon input. This carbon supply may fuel the synthesis of uptake related proteins, 
251 which are transcriptionally controlled by starvation related effectors (e.g. Crp) (You et al.,

252 2013). The carbon supply may also prime the cells metabolically for carbon uptake, for

253 example through high phosphoenolpyruvate (PEP) abundance. PEP is the substrate to

254 phosphorylate incoming glucose through the phosphotransferase system, the primary means

255 of rapid glucose uptake. While we did not measure PEP directly, we noticed differences in the

256 energy charges, AMP and ADP, between wild-type and the glycogen mutant during starvation

257 (Figure S4). Specifically, AMP and ADP were approximately 2.5 and 1.4 times more

258 abundant in the mutant compared to wild-type, respectively. Difference in charge are often

259 associated with changes in PEP abundance due to the dependence of PEP-associated

260 carboxylases and kinases on the energy charges (Sauer \& Eikmanns, 2005). In summary,

261 glycogen release enables cells to perform more rapid uptake: an important capability when

262 environments change often and nutrients are available only fleetingly.

From our findings, we propose a role for bacterial glycogen in dynamic environments. We found that glycogen is used to an appreciable magnitude in a short span of time ( $80 \%$ within 10 minutes), as glucose availability goes to zero. This demonstrates that glycogen is not merely a long-term energy storage that supplies microbial maintenance. Instead, glycogen is used within minutes for immediate physiological changes such as resumption of growth, induction of the attachment phase of biofilm formation, and to enable scavenging of nutrients. Furthermore, glycogen utilizing cells exhibited faster growth rates in dynamic environments, such as single nutrient shifts or repeated nutrient fluctuations, than glycogen-deficient cells.

273 Altogether, our data reveals glycogen as a crucial internal resource, consumed within minutes

274 of carbon starvation and synthesized within minutes of carbon re-availability, to aid in the physiological transitions that accompany environmental change. 
277 Environmental change imposes physiological challenges to bacteria. For example, in nutrient-

278 rich conditions, cells are not limited by their ability to scavenge nutrients. However, in

279 starvation, the opposite is needed - cells must take up diverse nutrients much more

280 efficiently (Towbin et al., 2017; You et al., 2013). The two scenarios result in a dilemma: the

281 cell has a contrarian objective after switching between carbon rich and poor conditions.

282 Meeting the new objective requires an appreciable change either in the abundance of key

283 proteins for uptake or to reconfigure the cells metabolically (e.g., elevated concentrations of

284 PEP). Our data depict glycogen as a solution: a fast, flexible store of nutrients. While inability

285 to use glycogen does not prevent cells from making physiological transitions, the ability to

286 use glycogen seems to quicken the rate at which transitions occur. Thus, we show that

287 glycogen is a facile resource for the cell to more quickly adjust its physiology to compete

288 more effectively in starvation and nutrient poor conditions. 
E. coli BW 25113 from the Keio collection (Baba et al., 2006) was used as the wild-type

(WT) strain for all experiments. Kanamycin markers were excised from the Keio knockout

strains $g \lg P, \operatorname{glg} A, g \lg B$, and $g \lg C$ using pCP20 and verified using PCR (Datsenko \& Wanner, 2000). All strains are listed in Table S1 and plasmids are listed in Table S2. Strains and plasmids are available from authors on request.

\section{Cultivation, media, and real-time metabolomics profiling}

299

300

301

302

303

Glucose media and culture preparation was followed as described in a previous study (Sekar et al., 2018). On the day before experiments, an inoculum of cells was prepared in sterile Luria-Bertani (LB) broth (10 g/L NaCl, $10 \mathrm{~g} / \mathrm{L}$ bacto-tryptone, and $5 \mathrm{~g} / \mathrm{L}$ yeast extract) in the morning and cultivated at $37^{\circ} \mathrm{C}$ with $225 \mathrm{RPM}$ shaking until noon. At noon, cells were 1:50 diluted into M9 minimal medium $+0.4 \%$ glucose. In the evening, shake flasks with $35 \mathrm{~mL}$ of M9 medium $+0.4 \%$ glucose were prepared with 1:100 dilution from the M9 inoculum and cultivated at $30^{\circ} \mathrm{C}$ with $225 \mathrm{RPM}$ shaking until the next morning. On the morning of the experiment, cells were typically OD 0.1 and then cultivated at $37^{\circ} \mathrm{C}$ with $225 \mathrm{RPM}$ shaking until they reached OD 0.8, at which point the experiments were commenced. The M9 minimal medium consisted of the following components (per liter): $7.52 \mathrm{~g} \mathrm{Na}_{2} \mathrm{HPO}_{4} \cdot 2 \mathrm{H}_{2} \mathrm{O}, 5 \mathrm{~g}$ $\mathrm{KH}_{2} \mathrm{PO}_{4}, 1.5 \mathrm{~g}\left(\mathrm{NH}_{4}\right)_{2} \mathrm{SO}_{4}, 0.5 \mathrm{~g} \mathrm{NaCl}$. The following components were sterilized separately and then added (per liter of final medium): $1 \mathrm{~mL} 0.1 \mathrm{M} \mathrm{CaCl}_{2}, 1 \mathrm{~mL} 1 \mathrm{M} \mathrm{MgSO}_{4}, 0.6 \mathrm{~mL} 0.1$ $\mathrm{M} \mathrm{FeCl}_{3}, 2 \mathrm{~mL} 1.4 \mathrm{mM}$ thiamine-HCL, and $10 \mathrm{~mL}$ trace salt solution. The trace salt solution

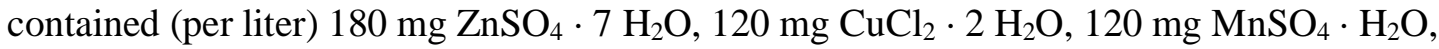
$180 \mathrm{mg} \mathrm{CoCl} 2 \cdot 6 \mathrm{H}_{2} \mathrm{O}$. The real-time metabolomics profiling is fully described in (Link et al., 2015), but briefly: Cells were cultivated in a Schott bottle submerged in a water bath 
controlled at $37^{\circ} \mathrm{C}$. Mixing and aeration were provided by a magnetic stirrer. A peristaltic pump circulated the culture through a six-port valve. On measurement, the valve configuration diverted roughly $2 \mu \mathrm{L}$ of culture into a continuous flow of negative ionization buffer (60:40 vol/vol isopropanol:water with $1 \mathrm{mM}$ ammonium fluoride, $\mathrm{pH} 9.0)$. The ionization buffer, now mixed with the live cells, was introduced for ionization in an electrospray chamber, and ions' abundances were measured semi-quantitatively using a

Quantitative Time of Flight mass spectrometry detector (Agilent 6550). Measurement (mixing of culture into the buffer) occurred every 15 seconds, thereby generating a time profile of the intracellular metabolic concentration. The annotation of ions is described in (Fuhrer, Heer,

Begemann, \& Zamboni, 2011).

\section{Real-metabolomics profiling of cells with depleting glucose}

Cells were grown to mid-log phase where the optical density (OD) at $600 \mathrm{~nm}$ was measured to 0.8 . At this point, $32.5 \mathrm{~mL}$ of the cells were collected on filter paper using fast filtration technique (Rabinowitz \& Kimball, 2007) and rapidly resuspended into $25 \mathrm{~mL}$ of pre-warmed 1:8 diluted M9 medium $\left(37^{\circ} \mathrm{C}\right)$ with $0.32 \mathrm{~g} / \mathrm{L}$ glucose as the sole carbon source within a

Schott bottle. Immediately after resuspension, the real-time metabolomics profile of the cells was measured for $1 \mathrm{~h}$.

To calculate the lag time of the glucose to acetate switch, cells were grown over night in M9 medium with glucose as carbon source at $37^{\circ} \mathrm{C}$. The next day, cells were freshly inoculated in M9 medium with glucose and grown until OD 0.4. The cells were transferred in M9 medium with acetate either directly or with an intermediate starvation period of $30 \mathrm{~min}$ in carbon free 
$341 \mathrm{~mL}$ Erlenmeyer flasks filled with $35 \mathrm{~mL}$ of acetate medium. To minimize the stress for the

342 cells, all equipment and solutions were prewarmed to $37^{\circ} \mathrm{C}$ and the transfer was performed

343 within less than two minutes. Cell growth was determined by measuring the $\mathrm{OD}_{600}$ by

344 spectrophotometry at $0,15,45,90,120 \mathrm{~min}$ and then every hour up to $420 \mathrm{~min}$ after

345 inoculation. The maximal growth rate was calculated using time-points after $240 \mathrm{~min}$ and lag

346 time was calculated as previously described (Enjalbert, Cocaign-Bousquet, Portais, \& Letisse,

347 2015).

Wild-type, $\triangle \operatorname{glg} P, \triangle g \lg A$ cells were grown over night at $37^{\circ} \mathrm{C}$ in Luria Broth (LB) until the

cells entered stationary phase. Cells were transferred to a non-shaking environment at room $\min$.

\section{Glycogen content experiments}

For the depletion experiment, wild-type cells were grown in M9 media and glucose until OD

0.5-0.8. Cells were rapidly transferred into M9 media without carbon source to initiate 
368 For the replenishment experiment, wild-type cells were grown in M9 media and glucose until

OD 0.5-0.8. After a starvation period of $30 \mathrm{~min}$ in M9 without carbon source, fructose $(200 \mathrm{~g} / \mathrm{L})$ and thiamine- $\mathrm{HCl}$ were added (alternative carbon source to avoid convolution with the assay). The samples were taken before the addition of fructose and $2 \mathrm{~min}, 5 \mathrm{~min}$ and 30 min after the addition and processed as described above. The glycogen content was measured with a fluorometric method as described in the MAK016 assay kit instructions (Sigma-

\section{Aldrich).}

The custom method of delivering controlled fluctuating nutrient environments is described in previous work (Nguyen, Fernandez, et al., 2019). In brief, microfluidic channels with a depth of $60 \mu \mathrm{m}$ were cast in polydimethylsiloxane (PDMS). Each PDMS (Sylgard 184; Dow

Corning) device was bonded to a glass slide by plasma treating each interacting surface for at least $1 \mathrm{~min}$, and the assembled chip then incubated for at least $2 \mathrm{~h}$ at $80^{\circ} \mathrm{C}$. The morning of each experiment, bonded channels were cooled to room temperature and then treated with a 1:10 dilution of poly-L-lysine (Sigma catalog no. P8920) in Milli-Q water. This treatment enhanced cell attachment but did not affect growth rate. Wild-type YFP cells and mutant CFP cells were grown over night in M9 medium with glucose and ampicillin. The cultures were then inoculated in fresh M9 medium with glucose and ampicillin. After growing until OD 0.5

$387-1.0$, the cells were filtered and transferred to a 1:8 diluted M9 medium without glucose 388 (starvation medium) to a final OD of 0.2. Afterwards, the cells were inoculated into the microchannel. Connecting all inputs and outputs to the microchannel took about 10-15 min, allowing ample time for cells to settle and attach to the glass surface within each 
carbon free MOPS medium (Teknova) separated by 30 s periods of $2 \%$ LB medium (100\%

394 LB diluted in MOPS medium). The same 2\% LB medium was steadily delivered to the non-

fluctuating control environment.

Image acquisition and analysis

Bacterial growth within the microfluidic channels was imaged using phase contract

401 final image resolution of $0.1083 \mu \mathrm{m}$ per pixel. Each position was repeatedly imaged every 3

402 min. Image series were processed using a custom MATLAB particle tracking pipeline, which identified individual particles based on pixel intensity and measured particle parameters, such as width and length. These size parameters were used to (1) filter particles that were associated with multiple cells or cells in close proximity to another and (2) approximate the volume of each single cell as a cylinder with hemispherical caps. The approximated volumes

407 were then used to compute instantaneous single-cell growth rates in terms of volume

408 doublings per hour. Using $V(t+\Delta t)=V(t) \cdot 2^{\mu \Delta t}$, we calculated $\mu$ between each pair of time points, associating the resulting $\mu$ with the latter of the two time points.

412 All data and code used for figure generation are available in Supplementary Data or at 413 https://github.com/karsekar/glycogen-starvation. 


\section{Figures}

415 Figure 1. Cells show secondary, glycogen-related metabolic activity upon carbon starvation.
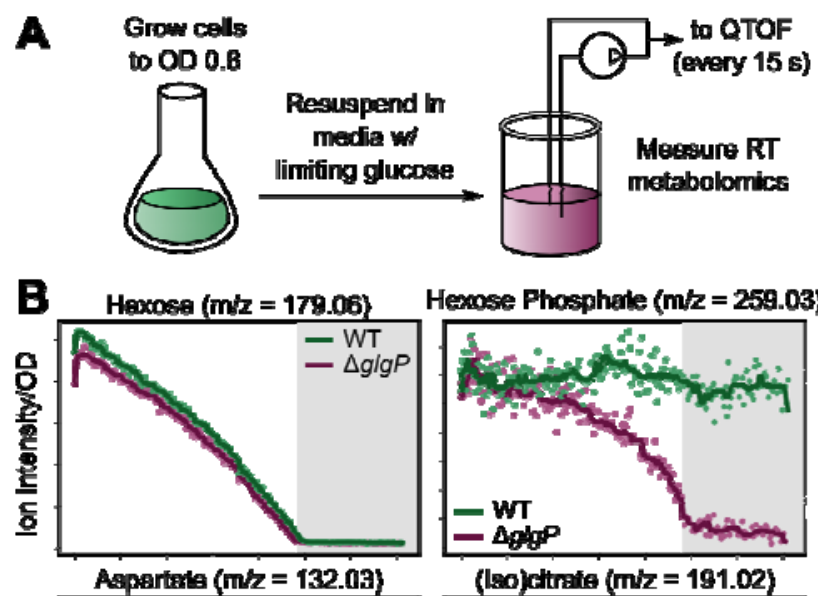

(A) Experimental setup for measuring metabolic profile of cells depleting carbon. Growing cells were switched to medium with limiting glucose $(0.32 \mathrm{~g} / \mathrm{L})$, then real-time metabolomics (Link et al., 2015) was measured for a total of $1 \mathrm{~h}$. For real-time metabolomics measurement, a pump circulated culture and injected $2 \mu \mathrm{L}$ of culture directly into a quantitative time of flight mass spectrometer every 15 s. (B) Glycogen mutant cells observe different metabolic activity on transition to starvation. Traces of exemplary ions are shown that correspond to hexose, hexose phosphate, aspartate, and (iso)citrate for two strains, WT (wild-type, green) and a $g \lg P$ mutant (purple). Dots indicate ion intensity measurement normalized to initial OD.

425 Gray area indicates the time period after glucose depletion. Solid lines are a moving average 426 filter of the measured ion intensity. 
429 Figure 2. Intracellular glycogen depletes rapidly after carbon downshift and accumulates

430 rapidly on carbon availability.

431
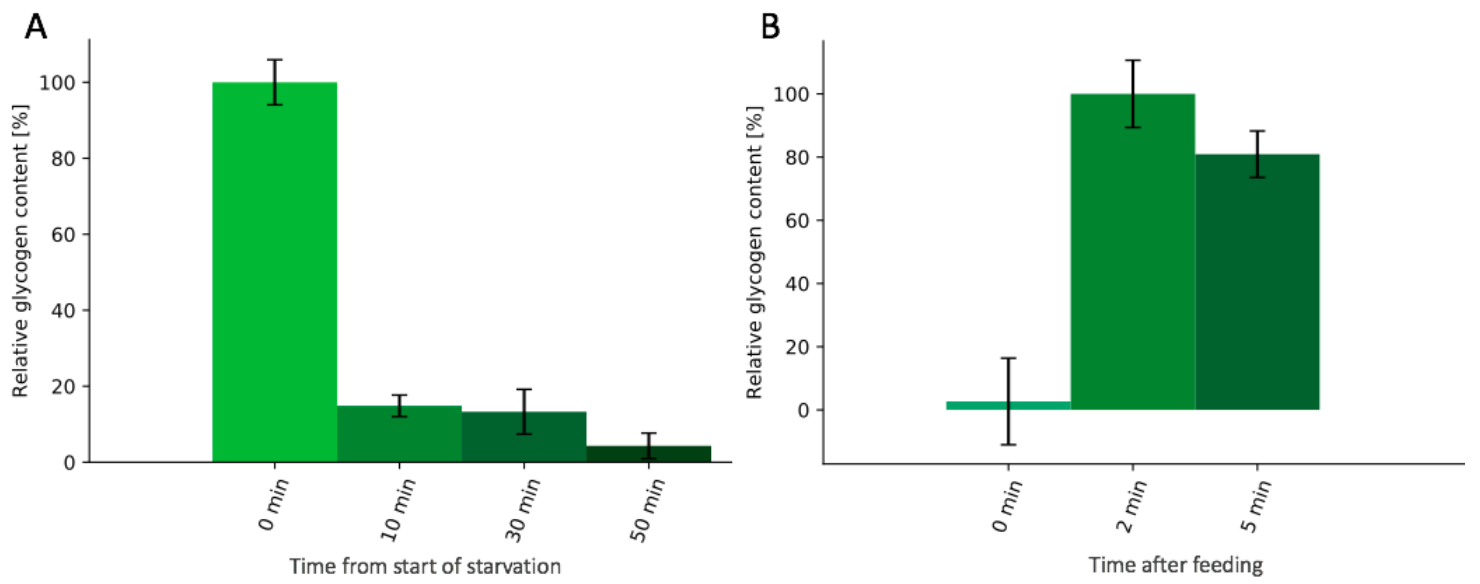

432 (A) Glycogen depletion during starvation. Wild-type cells were grown to mid-log phase (OD

433 0.8) and resuspended in medium without carbon. The first sample time point was taken before

434 resuspension. Error bars indicate the standard error of 6 biological replicates. (B) Rapid

435 glycogen synthesis upon fructose addition to a carbon starving culture. Fructose was added at

436 time point zero to wild-type E. coli harvest from mid-log phase (OD 0.8) after $30 \mathrm{~min}$

437 starvation in medium without carbon. Error bars indicate the standard error of 3 biological

438 replicates. 
440 Figure 3. A glycogen-related metabolic response occurs in response to brief, constant glucose

441 feed.

442

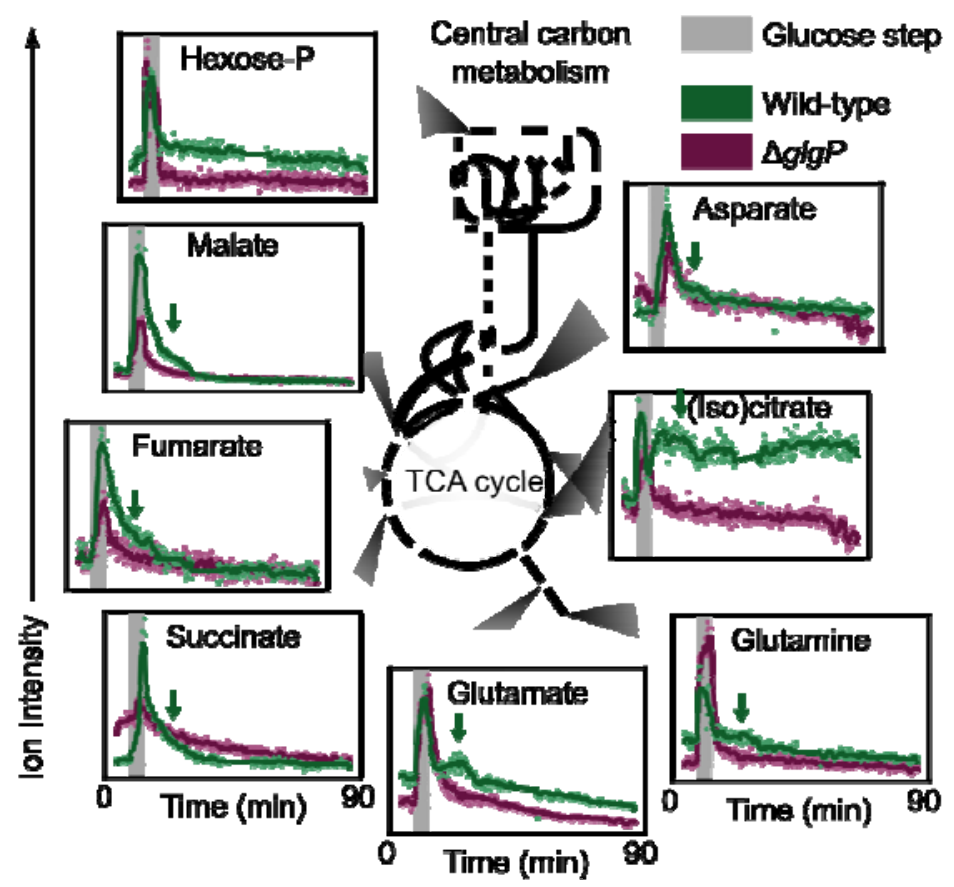

E. coli was grown to OD 0.8-1.2, starved for 30 min without glucose and fed a constant glucose supply. The glucose was supplied with a pump at a rate of $8 \mathrm{mmol} / \mathrm{g} / \mathrm{h}$ for two strains, WT (wild-type, green) and a $g l g P$ mutant (purple). After 5 min of glucose application, the glucose feed was ceased. Throughout the feed, real-time metabolomics measurement was performed, and data is shown for ions corresponding to central carbon metabolites. The green arrows indicate a metabolic "bounce" where measured ion intensity increases 5-15 minutes for metabolites malate, fumarate, succinate, glutamate, glutamine, (iso)citrate, and as paratate. Dots indicate ion intensity measurement normalized to initial OD. Gray area indicates the time period where glucose was supplied. Solid lines are a moving average filter of the measured ion intensity. 
456 Figure 4. Glycogen-related phenotypes in steady state versus changing conditions.

457
A

C
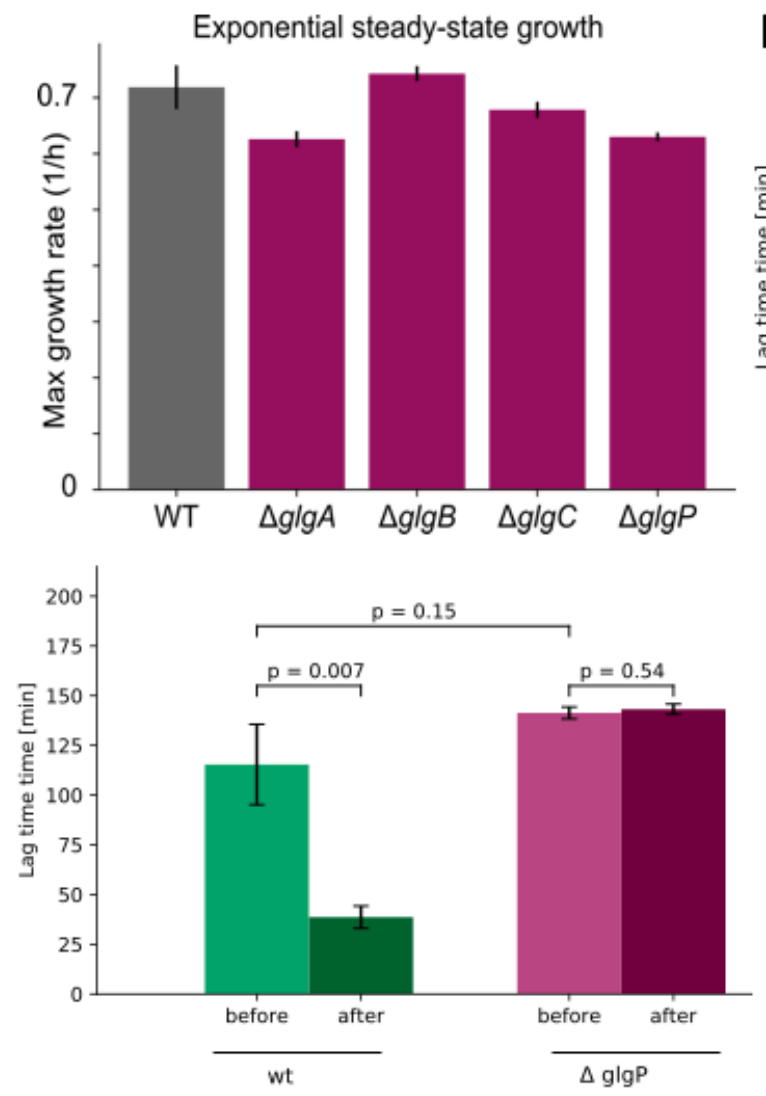
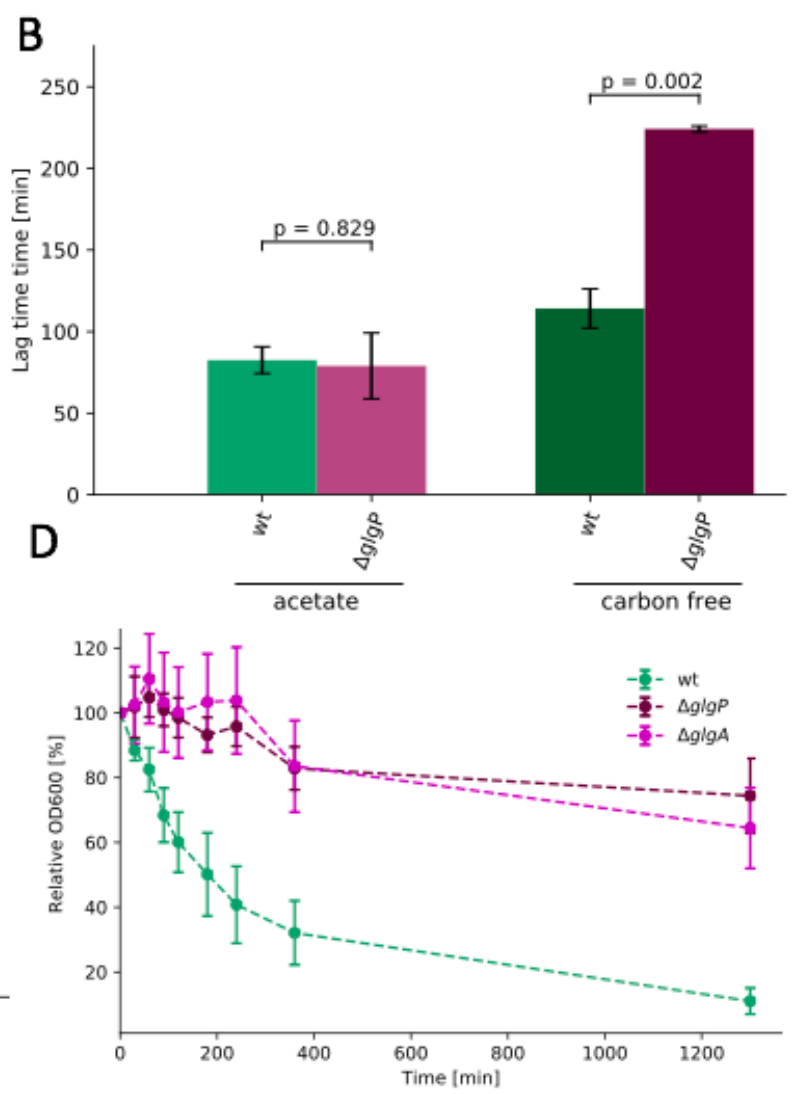

(A) Glycogen mutants exhibit similar growth rates to wild-type under steady-state growth.

(B) The $g \lg P$ glycogen mutant exhibits prolonged lag times when starved between nutrient transitions. Wild-type and $g \lg P$ mutant cells were grown to mid-log phase (OD 0.4) in glucose media. Cells were rapidly transferred into acetate medium either directly or with in-between $30 \mathrm{~min}$ period of starvation in carbon-free medium. The lag time until growth resumption was measured for all cells. Error bars indicate the standard error of 3 biological replicates, and P values were calculated assuming independence with Student's t test. (C) Wild-type and $g \lg P$ mutant cells were grown to mid-log phase (OD 0.4) in glucose media. Cells were rapidly transferred into acetate medium either $60 \mathrm{~min}$ before or $60 \mathrm{~min}$ after glucose depletion in the initial media. The lag time until growth resumption was measured for all cells.

(D) Glycogen mutants remained planktonic in stationary 
469 phase. Wild-type, $g \lg P$, and $g \lg A$ mutant cells were grown until stationary phase.

470 Afterwards, cells were cultivated without shaking to initiate biofilm formation. Cell $471 \quad$ attachment was measured via optical density. 

environments

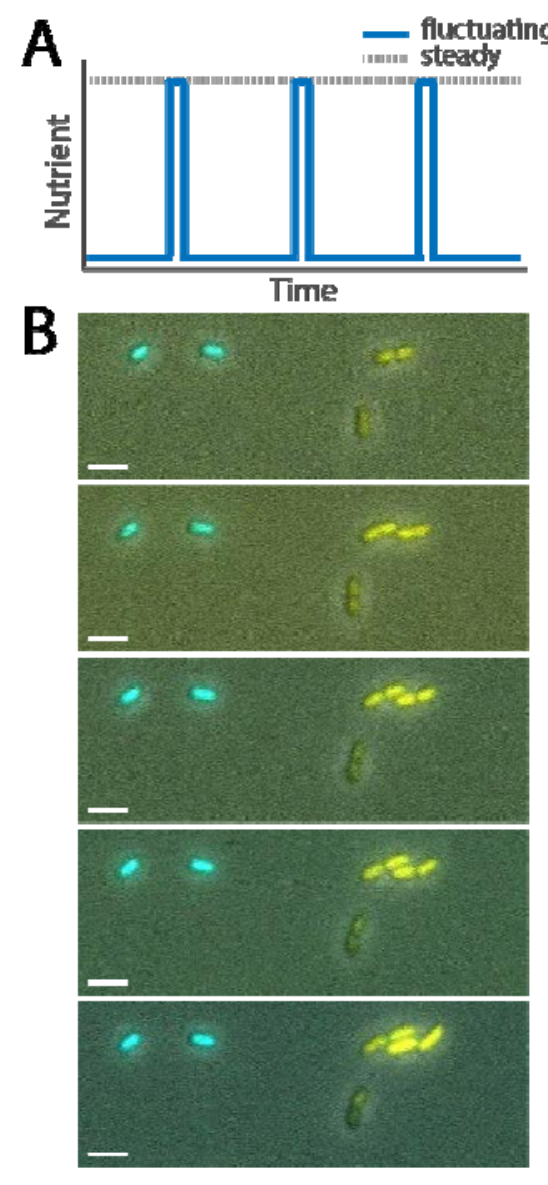

(A) Nutrient signals in pulsing and steady environments for microfluidic experiments.

Low phases of the fluctuating signal (blue) deliver zero carbon for $5 \mathrm{~min}$, while the maintains a constant concentration of $2 \%$ LB solution. (B) Montage of composite images from three channels: phase (grayscale), YFP (yellow) and CFP (cyan). Scale bar indicates $3 \mu \mathrm{m}$. (C) Growth rate over time from wild-type and $\Delta g \lg P$ populations within pulsing and steady environments. In both panels, curves represent the mean growth rate across replicate experiments; error bars represent standard deviation between replicates (three biological replicates across separate days for pulsing 
bioRxiv preprint doi: https://doi.org/10.1101/841718; this version posted November 14 2019. The copyright holder for this preprint (which was not certified by peer review) is the author/funder, who has granted bioRxiv a license to display the preprint in perpetuity. It is made available under aCC-BY-ND 4.0 International license.

condition; two biological replicates across separate days for steady). Each replicate

485 observed at least 1167 individual E. coli.

486 
487 Figure 6. Glycogen capability enables increased scavenging in starvation.

488

489

490

491

492

493

494

495

496

497

498

499

500

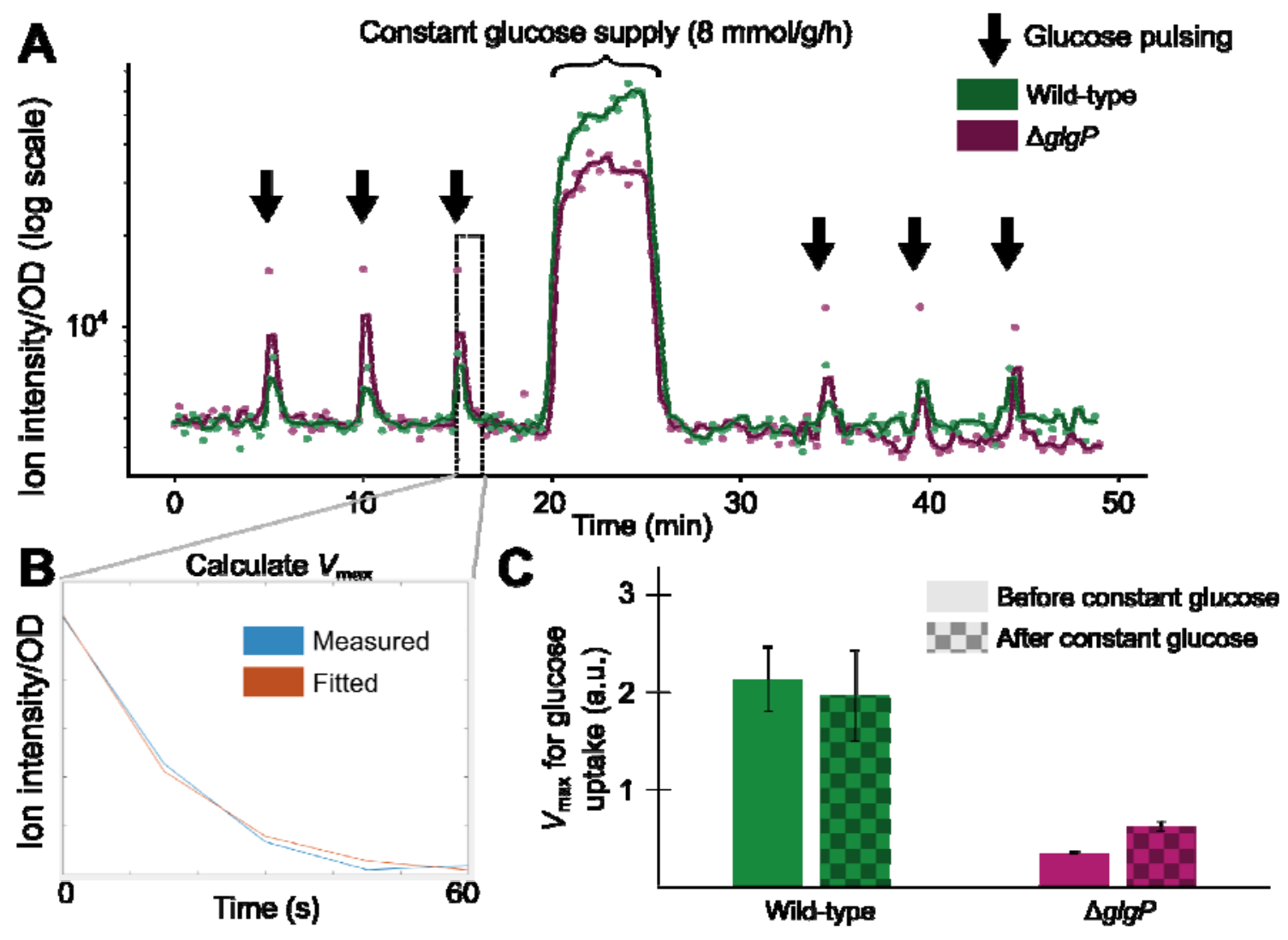

(A) Real-time metabolomics measurement of the ion corresponding to glucose in starved cells. Cells were grown to OD 0.8, then switched to media without carbon. Cellular metabolism was measured with real-time metabolomics as cells were pulse fed glucose every 5 minutes, an integrated feedrate of $\sim 0.4 \mathrm{mmol} / \mathrm{g} \mathrm{DCW} / \mathrm{h}$ (raw data available in

Supplementary Data). After $20 \mathrm{~min}$, a glucose was constantly supplied at $8 \mathrm{mmol} / \mathrm{g} / \mathrm{h}$ for 5 minutes. After the constant glucose supply, cells were pulse fed glucose again every 5 min. (B) The kinetics of the glucose uptake were fitted to a Michaelis-Menten equation in order to calculate $V_{\max }$ for every pulse. (C) The calculated $V_{\max }$ (scavenging ability) is much lower for a $g \lg P$ mutant compared to wild-type. The scavenging ability increases after the constant glucose supply for the $g \lg P$ mutant; whereas, the WT strain's scavenging ability is not improved. Error bars indicate the standard error of the glucose uptake rate for the pulses $(n=$ 3). Dots indicate ion intensity measurement normalized to initial OD. Gray area indicates the 
bioRxiv preprint doi: https://doi.org/10.1101/841718; this version posted November 14,2019 . The copyright holder for this preprint (which was not certified by peer review) is the author/funder, who has granted bioRxiv a license to display the preprint in perpetuity. It is made available under aCC-BY-ND 4.0 International license.

501 time period after glucose depletion. Solid lines are a moving average filter of the measured

502 ion intensity. 
Table S1. All strains used in this study.

\begin{tabular}{|c|c|c|}
\hline Strain & Genotype & Description \\
\hline $\begin{array}{l}\text { Wild-type } \\
\text { (WT) }\end{array}$ & $\begin{array}{l}\Delta(\text { araD-araB }) 567 \Delta(\text { rhaD-rhaB }) 568 \Delta \operatorname{lacZ4787(::rrnB-} \\
\text { 3)hsdR514 rph-1 }\end{array}$ & $\begin{array}{l}\text { BW } 25113 \\
\text { from (Baba et } \\
\text { al., 2006) }\end{array}$ \\
\hline$\triangle g \lg P$ & $\begin{array}{l}\text { Same as BW } 25113 \text { with } \triangle g l g P \text {. Kanamycin } \\
\text { marker was excised from corresponding strain from } \\
\text { (Baba et al., 2006). }\end{array}$ & glgP mutant \\
\hline$\Delta g \lg A$ & $\begin{array}{l}\text { Same as BW } 25113 \text { with } \triangle g l g A \text {. Kanamycin } \\
\text { marker was excised from corresponding strain from } \\
\text { (Baba et al., 2006). }\end{array}$ & $g \lg A$ mutant \\
\hline$\Delta g \lg B$ & $\begin{array}{l}\text { Same as BW } 25113 \text { with } \Delta g l g B . \text { Kanamycin } \\
\text { marker was excised from corresponding strain from } \\
\text { (Baba et al., 2006). }\end{array}$ & $g \lg B$ mutant \\
\hline$\triangle g \lg C$ & $\begin{array}{l}\text { Same as BW } 25113 \text { with } \Delta g l g C . \text { Kanamycin } \\
\text { marker was excised from corresponding strain from } \\
\text { (Baba et al., 2006) }\end{array}$ & $g \lg C$ mutant \\
\hline
\end{tabular}

506

Table S2. All plasmids used in this study.

\begin{tabular}{|l|l|l|}
\hline Plasmid & Description & Reference \\
\hline YFP & $\begin{array}{l}\text { Plasmid used to provide constitutive expression of yellow } \\
\text { fluorescence protein (pRSET-B YFP AddgeneID: } \\
\# 108856) .\end{array}$ & $\begin{array}{l}\text { (Sarabipour, } \\
\text { King, \& } \\
\text { Hristova, 2014) }\end{array}$ \\
\hline CFP & $\begin{array}{l}\text { Plasmid used to provide constitutive expression of cyan } \\
\text { fluorescein protein (pRSET-B CFP AddgeneID: } \\
\# 108858) .\end{array}$ & $\begin{array}{l}\text { (Sarabipour et } \\
\text { al., 2014) }\end{array}$ \\
\hline
\end{tabular}


509 Figure S1. Additional metabolic traces during glucose depletion.

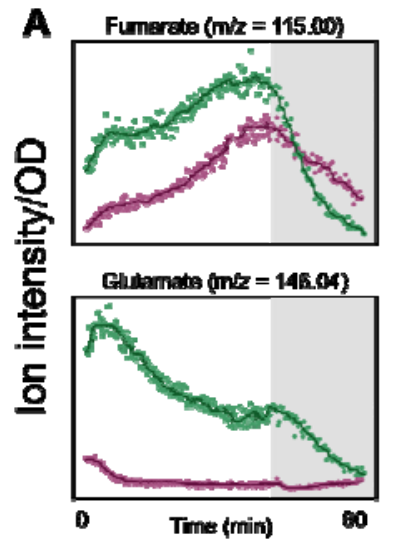

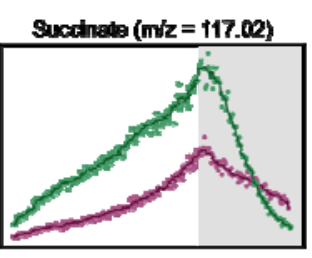

Makata $(m / 2=13901)$

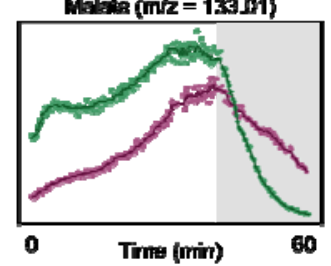

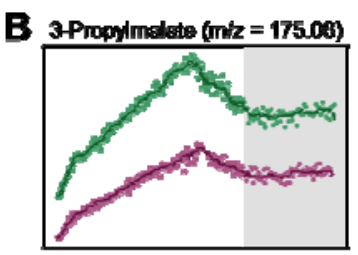

Ondatiantin $=155.01)$

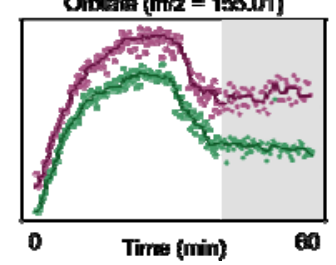

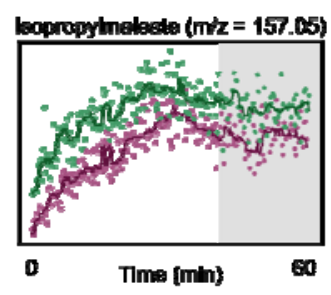

- WT

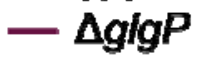

511 (A) Various metabolites in the TCA cycle deplete after glucose is depleted out of the media

512 regardless of glycogen capability. Two strains, WT (Wild-type, green) and a $\operatorname{glg} P$ mutant

513 (purple) are shown, as indicated by the color. Dots indicate ion intensity measurement

514 normalized to initial OD. Gray area indicates the time period after glucose depletion. Solid

515 lines are a moving average filter of the measured ion intensity. (B) Traces of exemplary ions

516 that remain constant after glucose depletion for both wild-type and $g \lg P$. 
518 Figure S2. The ion corresponding to glucose rises and falls with the availability of 519 glucose feed.

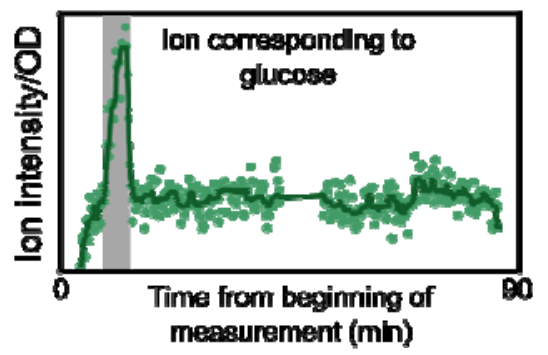

521 E. coli was grown to OD 0.8-1.2, starved for 30 min without glucose and fed a constant

522 glucose supply. The glucose was supplied with a pump at a rate of $8 \mathrm{mmol} / \mathrm{g} / \mathrm{h}$ for two strains,

523 WT (wild-type, green) and a $g \lg P$ mutant (purple). After 5 min of glucose application, the

524 glucose feed was ceased. Throughout the feed, real-time metabolomics measurement was

525 performed, and data is shown for ions corresponding to glucose as in Figure 3. Dots indicate

526 ion intensity measurement normalized to initial OD. Gray area indicates the time period

527 where glucose was supplied. Solid lines are a moving average filter of the measured ion

528 intensity. 
531 Figure S3. Additional ion traces for glucose step experiment.

532
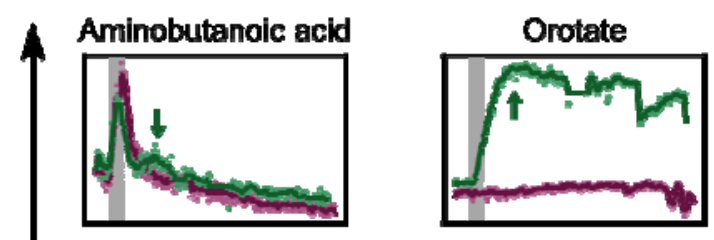

Phenylalanine

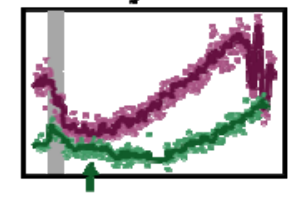

AMP

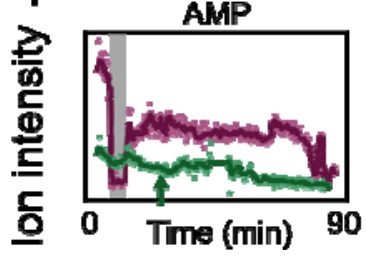

ADP

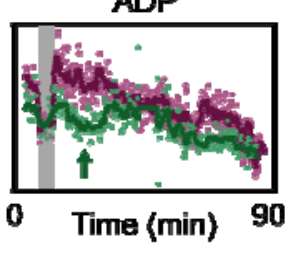

Glucose step

Wild-type

$\Delta g \mid g P$

E. coli was grown to OD $0.8-1.2$, starved for $30 \mathrm{~min}$ without glucose and fed a constant

534 glucose supply. The glucose was supplied with a pump at a rate of $8 \mathrm{mmol} / \mathrm{g} / \mathrm{h}$ for two strains,

535 WT (wild-type, green) and a $g \lg P$ mutant (purple). After 5 min of glucose application, the

536 glucose feed was ceased. Throughout the feed, real-time metabolomics measurement was

537 performed, and data is shown for ions corresponding to metabolites (aminobutanoic acid,

538 orotate, phenylalanine) and energy charges (AMP and ADP) as in Figure 3. Dots indicate ion

539 intensity measurement normalized to initial OD. Gray area indicates the time period where

540 glucose was supplied. Solid lines are a moving average filter of the measured ion intensity. 


\section{Author contributions}

544 K.S. conceived the project. All authors designed the experiments. K.S., S.M.L., J.N. and A.G.

545 developed the methodology, executed the experiments, and analyzed the data. U.S. and R.S.

546 supervised the work. K.S., S.M.L., and J.N. wrote the manuscript. All authors reviewed and

547 approved the manuscript.

550 We thank the Sauer laboratory members for useful comments and feedback on the

551 manuscript. We additionally thank T. Conway for discussions, and C. Gao for important 552 advice on the image analysis.

Baba, T., Ara, T., Hasegawa, M., Takai, Y., Okumura, Y., Baba, M., ... Mori, H. (2006). Construction of Escherichia coli K-12 in-frame, single-gene knockout mutants: The Keio collection. Molecular Systems Biology, 2, 2006.0008. https://doi.org/10.1038/msb4100050

Bergkessel, M., Basta, D. W., \& Newman, D. K. (2016). The physiology of growth arrest: Uniting molecular and environmental microbiology. Nature Reviews Microbiology, 14(9), 549-562. https://doi.org/10.1038/nrmicro.2016.107 
564 Bourassa, L., \& Camilli, A. (2009). Glycogen contributes to the environmental persistence and

565 transmission of Vibrio cholerae. Molecular Microbiology, 72(1), 124-138.

$566 \quad$ https://doi.org/10.1111/j.1365-2958.2009.06629.x

567 Datsenko, K. A., \& Wanner, B. L. (2000). One-step inactivation of chromosomal genes in Escherichia

568 coli K-12 using PCR products. Proceedings of the National Academy of Sciences of the United

$569 \quad$ States of America, 97(12), 6640-6645. https://doi.org/10.1073/pnas.120163297

570 Davidi, D., \& Milo, R. (2017). Lessons on enzyme kinetics from quantitative proteomics. Current

571 Opinion in Biotechnology, 46, 81-89. https://doi.org/10.1016/j.copbio.2017.02.007

572 Enjalbert, B., Cocaign-Bousquet, M., Portais, J.-C., \& Letisse, F. (2015). Acetate Exposure

573 Determines the Diauxic Behavior of Escherichia coli during the Glucose-Acetate Transition.

$574 \quad$ Journal of Bacteriology, 197(19), 3173-3181. https://doi.org/10.1128/JB.00128-15

575 Fuhrer, T., Heer, D., Begemann, B., \& Zamboni, N. (2011). High-throughput, accurate mass

576 metabolome profiling of cellular extracts by flow injection-time-of-flight mass spectrometry.

$577 \quad$ Analytical Chemistry, 83(18), 7074-7080. https://doi.org/10.1021/ac201267k

578 Jones, S. A., Jorgensen, M., Chowdhury, F. Z., Rodgers, R., Hartline, J., Leatham, M. P., ... Conway,

579 T. (2008). Glycogen and Maltose Utilization by Escherichia coli O157:H7 in the Mouse

580 Intestine. Infection and Immunity, 76(6), 2531-2540. https://doi.org/10.1128/IAI.00096-08

581 Kohanim, Y. K., Levi, D., Jona, G., Towbin, B. D., Bren, A., \& Alon, U. (2018). A Bacterial Growth

582 Law out of Steady State. Cell Reports, 23(10), 2891-2900.

$583 \quad$ https://doi.org/10.1016/j.celrep.2018.05.007

584 Li, S. H.-J., Li, Z., Park, J. O., King, C. G., Rabinowitz, J. D., Wingreen, N. S., \& Gitai, Z. (2018).

585 Escherichia coli translation strategies differ across carbon, nitrogen and phosphorus limitation

586 conditions. Nature Microbiology, 3(8), 939. https://doi.org/10.1038/s41564-018-0199-2

587 Link, H., Fuhrer, T., Gerosa, L., Zamboni, N., \& Sauer, U. (2015). Real-time metabolome profiling of https://doi.org/10.1038/nmeth.3584 
590

591

592

593

594

595

596

597

598

599

600

601

602

603

604

605

606

607

608

609

610

611

612

613

614

615

616

Mandel, M. J., \& Silhavy, T. J. (2005). Starvation for Different Nutrients in Escherichia coli Results in Differential Modulation of RpoS Levels and Stability. Journal of Bacteriology, 187(2), 434442. https://doi.org/10.1128/JB.187.2.434-442.2005

Metzl-Raz, E., Kafri, M., Yaakov, G., Soifer, I., Gurvich, Y., \& Barkai, N. (2017). Principles of cellular resource allocation revealed by condition-dependent proteome profiling. ELife, 6 , e28034. https://doi.org/10.7554/eLife.28034

Monk, J. M., Koza, A., Campodonico, M. A., Machado, D., Seoane, J. M., Palsson, B. O., ... Feist, A. M. (2016). Multi-omics Quantification of Species Variation of Escherichia coli Links Molecular Features with Strain Phenotypes. Cell Systems, 3(3), 238-251.e12. https://doi.org/10.1016/j.cels.2016.08.013

Mori, M., Schink, S., Erickson, D. W., Gerland, U., \& Hwa, T. (2017). Quantifying the benefit of a proteome reserve in fluctuating environments. Nature Communications, 8(1), 1225. https://doi.org/10.1038/s41467-017-01242-8

Morin, M., Ropers, D., Cinquemani, E., Portais, J.-C., Enjalbert, B., \& Cocaign-Bousquet, M. (2017). The Csr System Regulates Escherichia coli Fitness by Controlling Glycogen Accumulation and Energy Levels. MBio, 8(5). https://doi.org/10.1128/mBio.01628-17

Mutlu, A., Trauth, S., Ziesack, M., Nagler, K., Bergeest, J.-P., Rohr, K., ... Bischofs, I. B. (2018). Phenotypic memory in Bacillus subtilis links dormancy entry and exit by a spore quantityquality tradeoff. Nature Communications, 9(1), 69. https://doi.org/10.1038/s41467-017$02477-1$

Nguyen, J., Fernandez, V., Pontrelli, S., Sauer, U., Ackermann, M., \& Stocker, R. (2019). A bacterial physiology that enhance growth under rapid nutrient fluctuations. Under Review.

O’Brien, E. J., Utrilla, J., \& Palsson, B. O. (2016). Quantification and Classification of E. coli Proteome Utilization and Unused Protein Costs across Environments. PLoS Computational Biology, 12(6). https://doi.org/10.1371/journal.pcbi.1004998

Rabinowitz, J. D., \& Kimball, E. (2007). Acidic acetonitrile for cellular metabolome extraction from Escherichia coli. Analytical Chemistry, 79(16), 6167-6173. https://doi.org/10.1021/ac070470c 
617 Rahman, M., Hasan, M. R., Oba, T., \& Shimizu, K. (2006). Effect of rpoS gene knockout on the metabolism of Escherichia coli during exponential growth phase and early stationary phase based on gene expressions, enzyme activities and intracellular metabolite concentrations. Biotechnology and Bioengineering, 94(3), 585-595. https://doi.org/10.1002/bit.20858

Sander, T., Farke, N., Diehl, C., Kuntz, M., Glatter, T., \& Link, H. (2019). Allosteric Feedback Inhibition Enables Robust Amino Acid Biosynthesis in E. coli by Enforcing Enzyme Overabundance. Cell Systems, 8(1), 66-75.e8. https://doi.org/10.1016/j.cels.2018.12.005

Sarabipour, S., King, C., \& Hristova, K. (2014). Uninduced high-yield bacterial expression of fluorescent proteins. Analytical Biochemistry, 449, 155-157. https://doi.org/10.1016/j.ab.2013.12.027

Sauer, U., \& Eikmanns, B. J. (2005). The PEP-pyruvate-oxaloacetate node as the switch point for carbon flux distribution in bacteria. FEMS Microbiology Reviews, 29(4), 765-794.

Sekar, K., Rusconi, R., Sauls, J. T., Fuhrer, T., Noor, E., Nguyen, J., ... Sauer, U. (2018). Synthesis and degradation of FtsZ quantitatively predict the first cell division in starved bacteria. Molecular Systems Biology, 14(11), e8623. https://doi.org/10.15252/msb.20188623 High Affinity Binding and Allosteric Regulation ofEscherichia coli Glycogen Phosphorylase by the Histidine Phosphocarrier Protein, HPr. Journal of Biological Chemistry, 272(42), 26511-26521. https://doi.org/10.1074/jbc.272.42.26511

Shoemaker, W. R., \& Lennon, J. T. (2018). Evolution with a seed bank: The population genetic consequences of microbial dormancy. Evolutionary Applications, 11(1), 60-75. https://doi.org/10.1111/eva.12557

Tavormina, P. L., Kellermann, M. Y., Antony, C. P., Tocheva, E. I., Dalleska, N. F., Jensen, A. J., ... Orphan, V. J. (2017). Starvation and recovery in the deep-sea methanotroph Methyloprofundus sedimenti. Molecular Microbiology, 103(2), 242-252. https://doi.org/10.1111/mmi.13553 
644 Thomason, M. K., Fontaine, F., De Lay, N., \& Storz, G. (2012). A small RNA that regulates motility

645

646

647

648

649

650

651

652

653

654

655

656

657

658

659

660

661

662

663

664

665

666

667

668

669

and biofilm formation in response to changes in nutrient availability in Escherichia coli. Molecular Microbiology, 84(1), 17-35. https://doi.org/10.1111/j.1365-2958.2012.07965.x

Tian, Z., Fauré, A., Mori, H., \& Matsuno, H. (2013). Identification of key regulators in glycogen utilization in E. coli based on the simulations from a hybrid functional Petri net model. $B M C$ Systems Biology, 7(Suppl 6), S1. https://doi.org/10.1186/1752-0509-7-S6-S1

Towbin, B. D., Korem, Y., Bren, A., Doron, S., Sorek, R., \& Alon, U. (2017). Optimality and suboptimality in a bacterial growth law. Nature Communications, 8, 14123. https://doi.org/10.1038/ncomms14123

Wei, B., Shin, S., LaPorte, D., Wolfe, A. J., \& Romeo, T. (2000). Global Regulatory Mutations in csrA and rpoS Cause Severe Central Carbon Stress in Escherichia coli in the Presence of Acetate. Journal of Bacteriology, 182(6), 1632-1640.

Weiss, N., Obied, K. E. T. E., Kalkman, J., Lammertink, R. G. H., \& van Leeuwen, T. G. (2016). Measurement of biofilm growth and local hydrodynamics using optical coherence tomography. Biomedical Optics Express, 7(9), 3508-3518. https://doi.org/10.1364/BOE.7.003508

Wilson, W. A., Roach, P. J., Montero, M., Baroja-Fernández, E., Muñoz, F. J., Eydallin, G., ... Pozueta-Romero, J. (2010). Regulation of glycogen metabolism in yeast and bacteria. FEMS Microbiology Reviews, 34(6), 952-985. https://doi.org/10.1111/j.1574-6976.2010.00220.x

Yamamotoya, T., Dose, H., Tian, Z., Fauré, A., Toya, Y., Honma, M., .. Matsuno, H. (2012). Glycogen is the primary source of glucose during the lag phase of E. coli proliferation. Biochimica et Biophysica Acta (BBA) - Proteins and Proteomics, 1824(12), 1442-1448. https://doi.org/10.1016/j.bbapap.2012.06.010

You, C., Okano, H., Hui, S., Zhang, Z., Kim, M., Gunderson, C. W., ... Hwa, T. (2013). Coordination of bacterial proteome with metabolism by cyclic AMP signalling. Nature, 500(7462), 301306. https://doi.org/10.1038/nature12446 
bioRxiv preprint doi: https://doi.org/10.1101/841718; this version posted November 14 2019. The copyright holder for this preprint (which was not certified by peer review) is the author/funder, who has granted bioRxiv a license to display the preprint in perpetuity. It is made available under aCC-BY-ND 4.0 International license.

670 Zhao, R., Song, Y., Dai, Q., Kang, Y., Pan, J., Zhu, L., ... Shen, X. (2017). A starvation-induced

671 regulator, RovM, acts as a switch for planktonic/biofilm state transition in Yersinia

672

pseudotuberculosis. Scientific Reports, 7(1), 639. https://doi.org/10.1038/s41598-017-00534-9

673 